\title{
KOMUNIKASI INTERPERSONAL DI PT. PERKASA INTERNUSA MANDIRI MEDAN
}

\author{
Ester Hervina Sihombing, S.Sos., M.Si \\ Politeknik Unggul LP3M Medan \\ Jl.Iskandar Muda No.3 EF Medan-Sumatera Utara \\ www.politeknikunggul.ac.id, info@ politeknikunggul.ac.id
}

\begin{abstract}
Abstrak
Communication is an absolute necessity in the organization because communication can determine the communication would strengthen, unite or otherwise separate communication. In terms of communication among employees and leaders, if the communication that occurs either the employee will be able to acquire and develop the task in hand, so that the level of performance of an organization / company become better. Conversely, if there is poor communication due to good relations, authoritarian or indifferent attitude, disagreements or prolonged conflict, and so on. Communication has a very important influence on employee performance. Communication maintain the motivation to deliver information to employees about what to do, how well they are doing and what can be done to improve performance. One type of communication that is very important is the interpersonal communication, or communication that occurs between some personal face-to-face that allows ongoing verbal and nonverbal responses directly. In operation, the communication takes place on a reciprocal basis and produce feed back directly in response to a message. declared effective interpersonal communication when meeting communication is fun for the communicant so that if good interpersonal communication that occurs then the employee will be able to acquire and develop the task in hand, so that the level of performance of an organization become better.
\end{abstract}

Key word : Communication, Interpersonal Communication

\section{PENDAHULUAN}

\subsection{Latar Belakang}

Komunikasi merupakan kebutuhan yang mutlak dalam organisasi, apabila seseorang telah mengadakan hubungan yang tetap, maka sistem komunikasi yang mereka lakukan akan menentukan apakah sistem itu dapat mempererat atau mempersatukan, mengurangi ketegangan atau bahkan sebaliknya komunikasi akan memisahkan mereka jika komunikasi yang dilakukan tanpa dipikirkan akibatnya. Agar tercipta suasana yang saling mengerti, harmonis dan serasi, maka

seseorang yang hidup dan bekerjasama dengan orang lain harus mampu menyesuaikan sikap dan perilakunya dalam keadaan, waktu dan tempat di mana ia berada maka seseorang itu perlulah berkomunikasi dengan baik dimana komunikasi yang baik adalah komunikasi yang mengerti orang dan dimengerti oleh orang lain.

Komunikasi mempunyai pengaruh yang sangat penting terhadap kinerja pegawai. Komunikasi memelihara motivasi dengan memberikan penjelasan kepada para pegawai tentang apa yang harus dilakukan, seberapa baik mereka mengerjakannya dan apa yang dapat dilakukan untuk meningkatkan kinerja jika sedang berada di bawah standar. Aktivitas komunikasi di perkantoran senantiasa disertai dengan tujuan yang ingin dicapai. sesama dalam kelompok dan masyarakat. Salah satu jenis komunikasi yang sangat penting adalah komunikasi interpersonal atau komunikasi yang terjadi secara tatap muka antara beberapa pribadi yang memungkinkan respon verbal maupun nonverbal berlangsung secara langsung. Dalam operasionalnya, komunikasi berlangsung secara timbal balik dan menghasilkan feed back secara langsung dalam menanggapi suatu pesan.

Dalam hal komunikasi yang terjadi antar pegawai dan pimpinan, jika komunikasi yang terjadi baik maka pegawai akan mampu memperoleh dan mengembangkan tugas yang diembannya, sehingga tingkat kinerja suatu organisasi/perusahaan menjadi semakin baik. Sebaliknya, apabila terjadi komunikasi yang buruk akibat tidak terjalinnya hubungan yang baik, sikap yang otoriter atau acuh, perbedaan pendapat atau konflik yang berkepanjangan, dan sebagainya, dapat berdampak pada hasil kerja yang tidak maksimal. Peningkatan kinerja pegawai secara perorangan akan mendorong kinerja sumber daya manusia 
secara keseluruhan dan memberikan feed back yang tepat terhadap perubahan perilaku, yang direkflesikan dalam kenaikan produktifitas.

PT. Perkasa internusa Mandiri adalah perusahaan yang bergerak dalam bisnis distributor peralatan-peralatan yang diklasifikasikan ke dalam dua dividi seperti distributor alat-alat rumah tangga produk nasional dan Peralatan Industri Komersial. PT. Perkasa Internusa Mandiri telah mempunyai beberapa kantor cabang yang tersebar dibeberapa daerah seperti Bandung, Surabaya, Semarang, Bali, Makasar dan Medan. Dalam menjalankan perusahaan PT. Perkasa Internusa mandiri menjalankan Strategi perusahaan yang menitikberatkan pada pembaharuan sistem maupun peningkatan kemampuan sistem yang sudah berjalan guna membantu dunia usaha dalam mencapai keberhasilan yang diharapkan melalui komitment yang tinggi dalam mendistribusikan produk-produk bermutu dan selalu mengutamakan pelayanan bagi kepuasan pelanggan. Layanan PT. Perkasa Internusa Mandiri antara lain adalah membantu dunia usaha baik supplier maupun pelanggan dalam mencari dan menemukan produk-produk rumah tangga dan industri yang bermutu.

Untuk menunjang kelancaran jalannya kegiatan perusahaan dalam mendistribusikan produk rumah tangga dan industri maka komunikasi merupakan kebutuhan yang mutlak di PT. Perkasa Internusa Mandiri cabang Medan. Aktifitas komunikasi di perusahaan senantiasa disertai dengan tujuan yang ingin dicapai. Pendistribusian barang dari pusat ke cabangcabang dan ke supplier serta pelanggan harus tepat sasaran dan tepat waktu, untuk itu perlulah jalinan komunikasi interpersonal yang baik terjalin dalam perusahaan baik antara pimpinan dan bawahan dan sebaliknya.

Bertitik tolak dari uraian diatas, maka penulis tertarik untuk mengadakan penelitian dengan Judul " ANALISIS KOMUNIKASI INTERPERSONAL DI PT. PERKASA INTERNUSA MANDIRI MEDAN."

\subsection{Perumusan Masalah}

Berpedoman kepada latar belakang masalah, dapat diuraikan permasalahan yang dibahas dalam penulisan ilmiah ini : Bagaimana pelaksanaan Komunikasi Interpersonal di PT. Perkasa Internusa Mandiri Medan.

\subsection{Tujuan Penelitian}

Tujuan yang diinginkan dalam penulisan ini yakni : untuk mengetahui pelaksanaan Komunikasi Interpersonal di PT. Perkasa Internusa Mandiri Medan.

\subsection{Manfaat Penulisan}

Ada beberapa manfaat yang diambil dalam penelitian ini antara lain :

1. Secara akademis, penelitian ini diharapkan dapat menambah wawasan baru mengenai peranan komunikasi interpersonal dalam peningkatan prestasi kerja.

2. Penelitian ini dapat menjadi kontribusi dan acuan praktis bagi perusahaan dan masyarakat pada umumnya.

3. Sebagai bahan masukan dan bahan tambahan sumber pemikiran bagi PT. Perkasa Internusa Mandiri Medan.

\section{METODE PENELITIAN}

\subsection{Ruang Lingkup Penelitian}

Ruang lingkup penelitian ini meliputi : pelaksanaan komunikasi interpersonal yang akan membawa kepada prestasi kerja yang lebih baik.

\subsection{Tempat Penelitian}

Penelitian dilakukan di PT. Perkasa

Internusa Mandiri Medan di Jalan Kapten

Muslim 111 Milenium Medan

\subsection{Jenis dan Sumber Data}

Penelitian ini menggunakan data primer yang diperoleh dari wawancara dengan pegawai dan juga hasil pengamatan penulis dilapangan

\subsection{Teknik Pengumpulan Data}

Teknik pengumpulan data adalah cara mendapatkan informasi selengkaplengkapnya dari narasumber atau reponden. Teknik yang tepat akan mengefektifkan pengumpulan data, serta cara terbaik mendapatkan data yang akurat dan maksimal. Untuk melengkapi data yang diperlukan maka Penulis menggunakan alat/instrumen penelitian yaitu:

1. Observasi (Pengamatan)

Observasi merupakan pengamatan yang meliputi pemusatan perhatian terhadap suatu objek yang dilakukan dengan cara melihat secara langsung 
kepada kegiatan dari objek kantor tersebut dengan cara memantau aktifitas-aktifitas yang dilakukan di PT. Perkasa Internusa Mandiri Medan

2. Interview (wawancara)

Peneliti langsung mengadakan tanya jawab dengan pihak-pihak yang berkompeten langsung dengan penelitian untuk mendapatkan datadata yang penulis perlukan.

3. Studi Dokumen

Yaitu penelitian yang dilakukan dengan mengunakan dokumen dan bahan literatur lainnya sesuai dengan pembahasan penelitian penulis sebagai bahan rujukan dan pertimbangan.

\subsection{Teknik Analisis Data}

Metode analisa data yang dipergunakan dalam penulisan ini adalah : Metode deskriptif, yaitu suatu metode dimana data yang telah diproses, disusun, dikelompokkan, dianalisis, kemudian diinterpretasikan sehingga diperoleh gambaran tentang masalah yang dihadapi dan untuk menjelaskan hasil perhitungan. Data diperoleh dari data primer dan data sekunder.

\section{HASIL PEMBAHASAN}

Komunikasi interpersonal di PT. Perkasa Internusa Mandiri Medan dapat di bagi atas tiga bahagian antara lain

\section{A. Komunikasi Interpersonal Pimpinan terhadap Bawahan/Pegawainya.}

Secara umum PT. Perkasa Internusa Mandiri Medan dari tingkat pusat sampai ke perwakilan di cabang beberapa daerah seperti Bandung, Surabaya, Semarang, Bali, Makasar dsn Medan menggunakan sistem pemberian informasi sebagai berikut:

\section{Informasi ------Proses Komunikasi organisasi --------Komunikasi antar orang}

Komunikasi ke bawah menunjukkan arus pesan yang mengalir dari para atasan kepada bawahan. Bentuk yang paling umum adalah instruksi, memo resmi, pernyataan tentang kebijakan perusahaan, prosedur, pedoman kerja. Bentuk ini disampaikan hanya sampai ke Supervisor. Selanjutnya suprervisor langsung menyampaikan pesan informasi ke pegawai lapangan dalam bentuk komunikasi interpersonal. Secara umum komunikasi ke bawah yang dilakukan dari dari pusat yaitu Jakarta, harus masuk melalui organisasi secara keseluruhan di tiap Branch Office, sebagai kepala cabang yang bertugas mengkoordinasi bagian-bagian di wilayahnya dan melaporkan seluruh aktifitas cabang yang menyangkut perusahaan. Selanjutnya Branch Office menyampaikan informasi tersebut kepada Office Manager. Office Manager melakukan perintah Branch Office menyangkut kegiatan cabang perusahaan dan menganalisa kebutuhan perusahaan terhadap tenaga kerja diwilayah cabang.

Selanjutnya Office Manajer yang menyalurkan informasi tersebut ke supervisor untuk disampaikan dan dilaksanakan oleh pegawai. Hal ini sengaja dilakukan dan sama di setiap cabang dengan tujuan agar informasi yang disampaikan benar-benar sampai kepada pihak terkait untuk dilaksakan dengan baik.

Perusahaan menyadari bahwa salah satu kunci penting tercapainya tujuan perusahaan tergantung pada kemampuan pegawai dan supervisor untuk berkomunikasi secara efektif karena itu supervisor sangat disarankan untuk melakukan komunikasi interpersonal kepada pegawainya. Komunikasi interpersonal yang efektif terjadi apabila pesan yang disampaikan dimengerti dan dapat mendorong orang lain untuk bertindak sesuai dengan pesan yang disampaikan.

Berdasarkan hal diatas PT. Perkasa Internusa Mandiri Medan selalu mengembangkan iklim komunikasi yang terbuka dengan cara mengimplementasikannya dalam debirokratisasi organisasi, dengan menggunakan level arus pendek pada struktur organisasinya penyampaian komunikasi interpersonal menganggap semakin sedikit hubungan dalam rantai komunikasi, maka semakin kecil juga salah pengertian yang akan terjadi. Dengan kata lain, struktur yang datar ( semakin sedikit tingkatan) dan rentang kendali yang lebar (atasan mempunyai lebih banyak bawahan) semakin kecil kemungkinan terjadinya distorsi pesan dibandingkan struktur yang tinggi dan rentang kendali yang sempit. Struktur yang lebih datar membuat manager dapat berbagi informasi dengan rekan dan pegawai serta mengikutsertakan pegawai dalam membuat keputusan dengan memberikan kesempatan melakukan umpan balik atas informasi yang disampaikan. 
Biasanya supervisor dalam memberikan pesan menggunakan komunikasi interpersonal dengan pegawainya secara singkat, padat, jelas dan tepat sasaran dengan mengurangi kemungkinan ganda pada pesan yang dibuatnya.

Komunikasi interpersonal yang sering dilakukan oleh atasan kepada pegawainya selain berhubungan dengan pekerjaan pegawainya antara lain memberi arahan dan penjelasan rinci tentang produk yang akan didistribusikan . Selain itu komunikasi interpersonal juga di gunakan atasan dalam pemberian motivasi dan memperkuat loyalitas pegawai terhadap perusahaan, bahkan memberi nasehat masukan atau teguran langsung kepada pegawai.

Kesemua komunikasi interpersonal diatas di jalankan agar pegawai mengerti tugas yang harus dikerjakannya, alasan dan tujuan tugas tertentu, dan informasi mengenai perusahaan. Jika pegawai sudah mengerti terhadap tuga yang diberikan biasanya pegawai akan mau dan bersemangat mengerjakan tugas tersebut. Tugas yang dilaksanakan dengan penuh semangat akan menghasilkan produktivitas kerja yang baik. Jika pekerjaan pegawai selalu baik maka dapat dipastikan prestasi kerjanya akan baik.

Prestasi kerja sebagai hasil kerja (output) yang berasal dari adanya perilaku kerja serta lingkungan kerja tertentu yang kondusif. Pegawai dapat dikatakan tinggi prestasi kerjanya apabila karyawan yang bersangkutan telah menyelesaikan pekerjaannya atau telah memenuhi sasaran sesuai dengan yang ditargetkan oleh organisasi atau perusahaan.

\section{B. Komunikasi interpersonal antar pegawai.}

Komunikasi antar pegawai yang satu dengan yang lain atau komunikasi antar pegawai . Komunikasi ini terbagi atas dua bagian yaitu komunikasi horizontal dan komunikasi diagonal.

1. Komunikasi horizontal adalah pertukaran pesan antara orang-orang yang sama tingkatan otoritasnya di dalam organisai. Pesan ini biasanya berhubungan dengan tugas-tugas atau tujuan organisasi seperti koordinasi, pemecahan masalah dan saling member informasi. PT. Perkasa Internusa Mandiri Medan menerapkan komunikai interpersonal yang horizontal dengan tujuan tertentu antara lain:

a. Mengkoordinasi tugas-tugas. Perlu diskusi bagi tiap-tiap orang yang mempunyai kaitan kerja di bagian yang sama untuk dapat saling memberikan kontribusi dalam mencapai tujuan organisasi.

b. Saling berbagi informasi untuk perencanaan. Ide dari banyak orang biasanya akan lebih baik daripada ide satu orang.

c. Memecahkan masalah yang timbul diantara orang-orang yang berada dalam tingkatan/ bidang yang sama.

d. Menjamin pemahaman yang sama terhadap tugas yang dikerjakan bersama.

e. Mengembangkan dukungan interpersonal, karena sebahagian besar dari waktu kerja pegawai berinteraksi dengan temannya maka memreka perlu saling memberikan dukungan hubungan interpersonal.

2. Komunikasi Diagonal merupakan komunikasi silang menlintasi fungsi dan tingkat dalam organisasi. Di PT. Perkasa Internusa Mandiri Medan komunikasi juga sangat sering menggunakan komunikasi diagonal karena tugas masing-masing pegawai adalah tugas yang hampir seperti suatu sistem yang saling membutuhkan, karena itu harus diakui komunikasi diagonal ini juga merupakan kegiatan penting dalam situasi dimana para nggota tidak dapat berkomunikasi secara efektif khususnya dalam rangka tugas mereka yang sama-sama sebagai tenaga pembuat software, hardware dan jaringan dimana ketiganya merupakan perangkat yang saling berhubungan sebagai suatu sistem serta tenaga pengajar bagi perusahaan yang membutuhkan jasa mereka.

\section{Komunikasi Interpersonal dari Bawah ke Atas}

Komunikasi ke atas adalah pesan yang mengalir dari bawahan kepada atasan dalam hal ini supervisor. Komunikasi interpersonal yang sering dilakukan pegawai PT. Perkasa 
Internusa Mandiri Medan biasanya mengenai pekerjaan yang akan mereka kerjakan atau pekerjaan yang sedang dikerjakan atau yang akan mereka kerjakan. Pegawai biasanya langsung bertanya kepada supervisor jika ada pekerjaan yang masih belum mengerti untuk dilaksanakan.

Namun tak jarang juga pegawai memberikan ide, pikiran, saran atau masukan kepada supervisor untuk perusahaan, dan supervisor akan menyampaikan kepada office Manajer untuk selanjutnya disampaikan kepada Branch Office dan Branch Office lah yang menyampaikan kepada organisasi di tingkat pusat.

Supervisor haruslah mendapatkan informasi dari bawahannya mengenai hal- hal berikut ini :

1. Hal-hal apa saja yang harus dilakukan bawahan

2. Menjelaskan persoalan-persoalan kerja yang belum terpecahkan.

3. Memberikan saran atau gagasan untuk perbaikan organisasi.

4. Mengungkapkan bagaimana pikiran dan persasaan mereka tentang pekerjaan yang diberikan.

Ada beberapa fungsi yang di dapat oleh perusahaan PT. Perkasa Internusa Mandiri Medan dalam melaksanakan komunikasi interpersonal ke atas antara lain :

a. Supervisor dan atasan ditiap tingkatan dapat mengetahui kapan pegawai siap untuk diberi tugas dan bagaimana sebaiknya cara atasan member pesan kepada bawahan.

b. Pegawai dapat member informasi yang berharga kepada pembuat keputusan sampai tingkat tertinggi di PT. Perkasa Internusa Mandiri Medan

c. Memperkuat apresiasi dan loyalitas karyawan terhadap organisasi dengan memberikan kesempatan untuk mengajukan ide dan saran tentang jalannya perusahaan.

d. Agar supervisor dapat menentukan apakah pegawainya dapat megerti arti pesan yang dia sampaikan

e. Membantu pegawai itu sendiri untuk mengatasi masalah-masalah pekerjaan mereka dan memperkuat keterlibatan mereka dalam tugas-tugasnya.

Aktifitas komunikasi interpersonal di PT. Perkasa Internusa Mandiri Medan dari komunikasi interpersonal antara atasan kepada bawahan, komunikasi interpersonal antara pegawai yang satu dengan pegawai yang lain, komunikasi interpersonal antara bawahan kepada atasan telah berjalan dengan baik ini dapat di lihat dari semangat kerja dan motivasi pegawai yang cukup tinggi untuk menyelesaikan pekerjaan tepat waktu dan rendahnya tingkat kemangkiran dalam bekerja. Rasa semangat dan motivasi itu muncul karena pegawai merasa komunikasi interpersonal cukup baik apalagi perusahaan menerapkan komunikasi iklim terbuka sehingga semua itu berdampak terhadap prestasi kerja mereka yang semakin baik.

\section{KESIMPULAN DAN SARAN 4.1 Kesimpulan}

1. Komunikasi merupakan kebutuhan yang mutlak dalam organisasi, apabila seseorang telah mengadakan hubungan yang tetap, maka sistem komunikasi yang mereka lakukan akan menentukan apakah sistem itu dapat mempererat atau mempersatukan, mengurangi ketengangan atau bahkan sebaliknya komunikasi akan memisahkan mereka jika komunikasi yang dilakukan tanpa dipikirkan akibatnya.

2. komunikasi interpersonal ( komunikasi antar pribadi) adalah komunikasi yang berlangsung antara dua orang atau lebih dalam suatu usaha menyampaikan pesan dimana pesan tersebut disampaikan secara tatap muka ( face to face ) dan dilakukan secara berulang untuk berhubungan dengan orang lain.

3. PT. Perkasa internusa Mandiri adalah perusahaan yang bergerak dalam bisnis distributor peralatanperalatanyang diklasifikasikan ke dalam dua dividi seperti distributor alat-alat rumah tangga produk nasional dan Peralatan Industri Komersial. Layanan PT. Perkasa Internusa Mandiri antara lain 
adalah membantu dunia usaha baik supplier maupun pelanggan dalam mencari dan menemukan produkproduk rumah tangga dan industri yang bermutu.

4. Komunikasi merupakan kebutuhan yang mutlak PT. Perkasa Internusa Mandiri Medan dan peran komunikasi interpersonal sangat penting dalam menunjang kelancaran jalannya kegiatan perusahaan. Aktifitas komunikasi interpersonal PT. Perkasa Internusa Mandiri Medan dapat dilihat dari berbagai sisi. Sisi pertama adalah komunikasi antara atasan kepada bawahan. Sisi kedua antara pegawai yang satu dengan pegawai yang lain. Sisi ketiga adalah antara bawahan kepada atasan.

\subsection{Saran}

1. komunikasi antar pribadi atasan kepada bawahan, komunikasi antar pribadi pegawai yang satu dengan pegawai yang lain, komunikasi antar pribadi antara bawahan kepada atasan yang telah dilaksanakan dengan baik agar tetap selalu dipelihara, dan bila perlu senantiasa ditingkatkan demi kemajuan perusahaan.

2. Seluruh pegawai hendaknya dapat menjalin hubungan kerja yang harmonis serta tanggap terhadap segala bentuk situasi dan kondisi di lingkungan kerja dan juga mampu meningkatkan prestasi kerjanya masing-masing.

\section{DAFTAR PUSTAKA}

Alo, Liliweri, 1997, Komunikasi Antarpribadi, Penerbit Citra Aditya, Bandung.

Arifin, Anwar, 2003, Ilmu Komunikasi Sebuah Pengantar Ringkas, Penerbit Raja Grafindo Persada, Jakarta.

Arikunto, Suharsimi, 1998, Prosedur Penelitian Suatu Pengantar Praktis, Penerbit Rineka Cipta, Jakarta.

Devito Joseph A, 1997, Komunikasi Antar Manusia, Penerbit Profesional book, Jakarta.

Departemen Pendidikan dan Kebudayaan,
1986, Kamus Besar Bahasa Indonesia, Penerbit Balai Pustaka, Jakarta.

Efendy, Onong U, 2000, Ilmu Teori dan Filsafat Komunikasi, Penerbit PT.Raja Grafindo Persada, Jakarta.

1993, Dinamika Komunikasi, Penerbit Remaja Rosdakarya, Bandung. 1992, Ilmu Komunikasi

Teori dan Praktek, Remaja Rosdakarya, Bandung.

Fisher, Aubrey, 1986 Teori-teori Komunikasi, Remaja Rosdakarya, Bandung.

Rakhmat, Jalaluddin, 1992, Psikologi Komunikasi, Bandung. 